BMC

Genomics

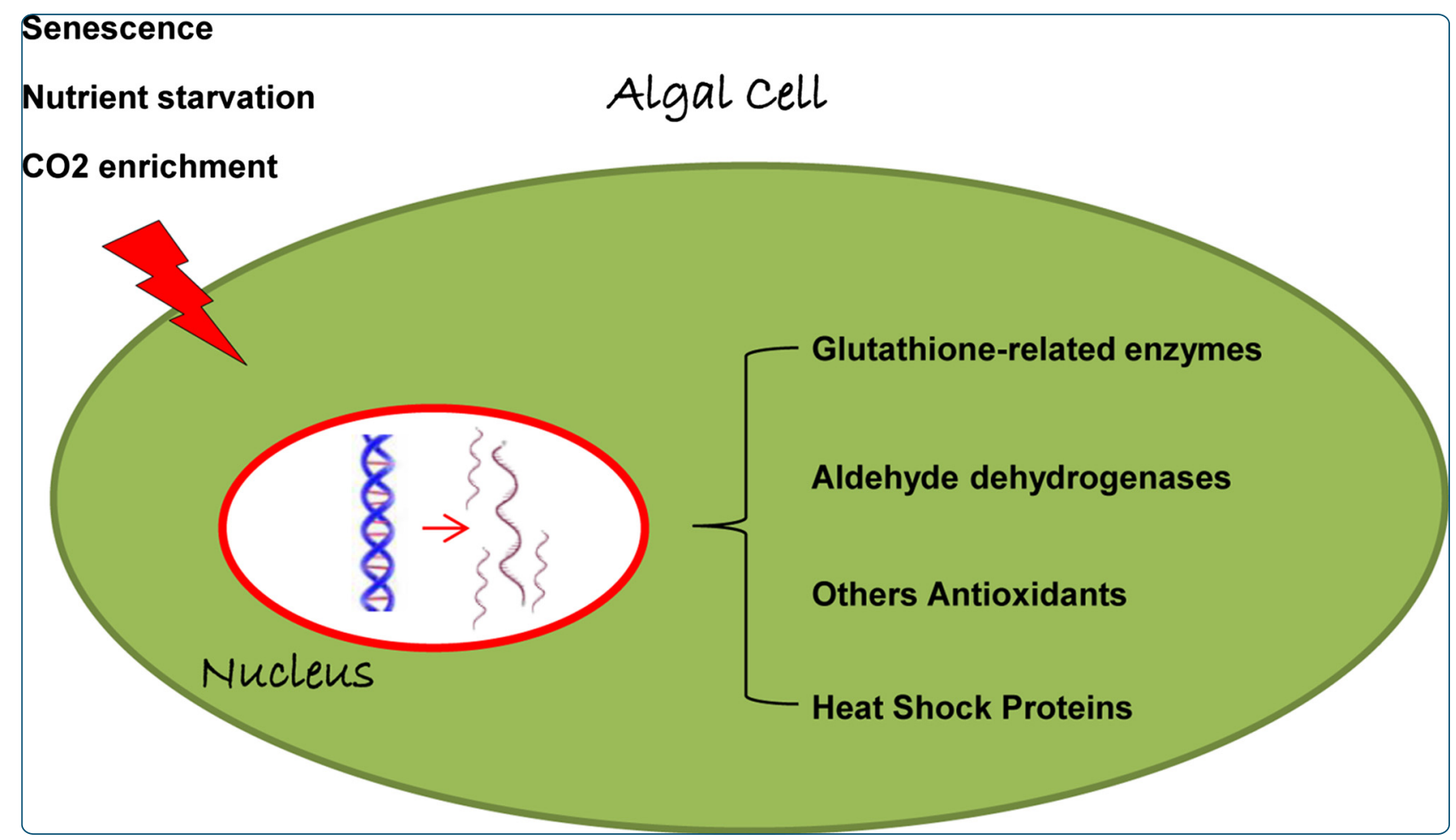

\title{
Key genes as stress indicators in the ubiquitous diatom Skeletonema marinoi
}

Lauritano et al. 


\title{
Key genes as stress indicators in the ubiquitous diatom Skeletonema marinoi
}

\author{
Chiara Lauritano*, Ida Orefice, Gabriele Procaccini, Giovanna Romano and Adrianna lanora
}

\begin{abstract}
Background: The dense phytoplankton blooms that characterize productive regions and seasons in the oceans are dominated, from high to low latitudes and from coast line to open ocean, by comparatively few, often cosmopolitan species of diatoms. These key dominant species may undergo dramatic changes due to global climate change.

Results: In order to identify molecular stress-indicators for the ubiquitous diatom species Skeletonema marinoi, we tested stress-related genes in different environmental conditions (i.e. nutrient starvation/depletion, $\mathrm{CO}_{2}$-enrichment and combined effects of these stressors) using RT-qPCR. The data show that these stressors impact algal growth rate, inducing early aging and profound changes in expression levels of the genes of interest.

Conclusions: Most analyzed genes (e.g. antioxidant-related and aldehyde dehydrogenases) were strongly down-regulated which may indicate a strategy to avoid unnecessary over-investment in their respective proteins. By contrast, key genes were activated (e.g. HSPs, GOX) which may allow the diatom species to better cope with adverse conditions. We propose the use of this panel of genes as early bio-indicators of environmental stress factors in a changing ocean.
\end{abstract}

Keywords: Diatoms, Stress-related genes, Molecular indicators, Nutrient starvation, Ocean acidification

\section{Background}

Diatoms are eukaryotic unicellular plants that constitute one of the major components of marine phytoplankton [1] comprising up to $40 \%$ of annual productivity at sea [2] and representing up to $25 \%$ of global carbon-fixation [3]. Natural (e.g. cold/heat and nutrient limitation) and/or anthropogenic (e.g. ocean acidification and pollutants) factors may alter the physiology and survival of diatoms, thereby influencing current levels of ocean primary productivity $[4,5]$. Here we use Reverse Transcriptionquantitative PCR (RT-qPCR) to identify key genes as indicators of defense processes activated in response to various stressful conditions in the ubiquitous diatom Skeletonema marinoi, a species which forms massive blooms in many of the world's coastal oceans [6-8]. Previous studies on S. marinoi have focused on its genetic structure [8], secondary metabolite production [9], physiological response to nutrient limitation [10] and interactions with zooplankton species $[6,7,11,12]$. This is the first

\footnotetext{
* Correspondence: chiara.lauritano@szn.it

Stazione Zoologica Anton Dohrn, Villa Comunale, 80121 Napoli, Italy
}

study focusing on stress-related genes as health-status indicators in this diatom species.

The stress conditions tested were senescence, silicic acid limitation/starvation, $\mathrm{CO}_{2}$-enrichment and the combination of these conditions. Si-concentrations vary extensively in the world's oceans, depending on the regions and depths analyzed [13] and it is generally assumed that biogenic silicate content of some diatoms decreases under ocean acidification conditions [14]. Since diatoms incorporate inorganic silicon into the cell as silica [15] and use it to construct their outer cell wall, the availability and distribution of silicic acid can strongly modify diatom growth and population dynamics [16]. Hence we hypothesized that the combination of ocean acidification and variations in silicic acid availability would potentially negatively impact diatom growth and modify stress gene expression levels [14,16-18].

Current levels of atmospheric $\mathrm{CO}_{2}$ are predicted to be more than double by 2100 (Intergovernmental Panel on Climate Change IPCC 2007). Studies have reported contrasting results on the effects of ocean acidification in different phytoplankton species. Some studies speculate 
that larger diatoms will be favored [15], while others suggest that diatoms may age faster and undergo senescence/aging or even disappear in some areas of the oceans [18].

In order to test the effects of these two stressors (changes in silicic acid and $\mathrm{CO}_{2}$ levels), we selected a panel of genes involved in both first [19] and second lines of defense [20,21]: ATP-binding cassette transporter $(\mathrm{ABC})$, aldehyde dehydrogenases (ALDH), succinate dehydrogenase (SSD), betaine ALDH (BALDH), glutathione synthase (GSH-S), glutathione peroxidase (GPX), glutathione reductase (GR), glutathione S-transferase (GST), catalase (CAT), superoxide dismutase (SOD), ascorbate peroxidase (AP) and tocopherol cyclase (TOCC) (see Additional file 1 for details). We also analyzed glycolate oxidase (GOX), an enzyme involved in stress resistance in the higher plant Arabidopsis thaliana [22] and some of the major families of heat shock proteins (HSP70, HSP90 and luminal binding protein or LBP), molecular chaperones known to be involved in the stress response induced by various environmental factors such as heat, cold, hypoxia, UV radiation and aging [23]. Activation of all these genes is known to help adjust cellular physiology and metabolism to changing conditions by offering protection against cell damage or death in other organisms [19-23].

\section{Results Aging}

Here we show that all the stress conditions tested (nutrient starvation/depletion, $\mathrm{CO}_{2}$-enrichment and combinations) induced early aging in $S$. marinoi, as shown by net growth rates, which were $0.76 \pm 0.05 \mathrm{~d}^{-1}$ for Si-starvation, $0.16 \pm 0.01 \mathrm{~d}^{-1}$ for Si-depletion, $0.78 \pm 0.005 \mathrm{~d}^{-1}$ for $\mathrm{CO}_{2}$ enrichment and $0.59 \pm 0.007 \mathrm{~d}^{-1}$ for $\mathrm{CO}_{2}$-enrichment in combination with $\mathrm{Si}$-starvation (referred to as $\mathrm{CO}_{2}-\mathrm{Si}$ ) conditions, compared to the control $0.88 \pm 0.02 \mathrm{~d}^{-1}$ (considering the growth rate between day 1 and day 7 for each condition). At the gene level, HSP expression levels increased in the stationary (STAT) and decline (DECL) phases of the growth curves in each studied condition (see Figure 1). Gene expression levels in the exponential phase (EXP) have been used as control condition for each RT-qPCR analysis shown in Figure 1 (the control condition is represented by the $\mathrm{x}$-axis in the bar graph). The increase was time dependent, with the highest upregulation in the declining phase of growth. In particular, in the growth curve of algae cultured with complete medium (Figure 1a), HSP70_1 and HSP70_4 were 2-fold up-regulated ( $\mathrm{p}<0.05$ and $\mathrm{p}<0.01$, respectively), while HSP90 was significantly 3 -fold up-regulated $(\mathrm{p}<0.001)$ in STAT. In the DECL phase, HSP70_1 and HSP70_4 were 3 -fold up-regulated $(\mathrm{p}<0.001)$, while HSP90 expression levels increased by 4 -fold $(\mathrm{p}<0.001)$. The same pattern was observed for HSP expression level in the growth curve of algae grown in Si-starvation (Figure $1 \mathrm{~b}$ ) and in $\mathrm{CO}_{2}$-Si conditions (Figure 1c). Also in these cases, there was a time-dependent increase, but the upregulation was statistically significant only for HSP90 ( $\mathrm{p}<0.05$ in STAT and $\mathrm{p}<0.001$ in DECL) in Si-starvation (Figure 1b) and for HSP70_1 ( $p<0.001$ in DECL) and HSP70_4 ( $p<0.05$ in STAT and $\mathrm{p}<0.001$ in DECL) in $\mathrm{CO}_{2}$-Si condition (Figure 1c). Aging did not induce variations in other gene categories, with some exceptions. The Glutathione-related enzymes GSH-S, GR and GST expression levels were higher in STAT and DECL phases in algae grown in complete medium ( $p>0.05$, see Figure 1a for details), while GPX was down-regulated in both phases $(p<0.01)$ compared to the EXP one (Figure 1a). GR also was significantly up-regulated in DECL of the $\mathrm{CO}_{2}-\mathrm{Si}$ growth curve $(\mathrm{p}<0.001$; Figure $1 \mathrm{c})$. $\mathrm{ABC}$ also increased in STAT and DECL in the complete medium curve $(\mathrm{p}<0.05$; Figure 1a). AP and BALDH increased in STAT and DECL $(\mathrm{p}<0.001$ for AP in both STAT and DECL, and $\mathrm{p}<0.01$ for BALDH in both STAT and DECL), GR and ALDH2 in DECL $\left(\mathrm{p}<0.001\right.$ and $\mathrm{p}<0.01$, respectively) in the $\mathrm{CO}_{2}$-Si growth curve (Figure 1c).

\section{Nutrient starvation/depletion}

Figure 2a shows gene expression changes in S. marinoi grown in Si-starvation, while $2 \mathrm{~b}$ in Si-depletion condition. For both RT-qPCR analyses, gene expression levels of algae grown in complete medium have been used as control condition (in the bar graph the control condition is represented by the $\mathrm{x}$-axis). In $\mathrm{Si}$-starvation, there was the down-regulation of almost all the genes of interest (Figure 2a). HSP90 and SSD were the only genes that were down-expressed in EXP $(\mathrm{p}<0.001$ and $\mathrm{p}<0.05$, respectively). HSP70_4, HSP90, ALDH2 and GSH-S were down-regulated in STAT $(\mathrm{p}<0.001$ for HSP90 and $\mathrm{p}<$ 0.05 for the others). In DECL, many genes showed decreased expression levels: HSP70_4, HSP90, ALDH2, SSD, BALDH, GSH-S, GPX, GR, SOD and ABC ( $p<0.05$ for HSP70_4, ALDH2, SSD and GPX, p $<0.01$ for GR and $\mathrm{p}<0.001$ for the others). HSP90 was the most affected gene, with a decrease of more than 4-fold. In Si-depletion condition, the down-regulation was even more pronounced, with a reduction of more than 8-fold for ALDH2 (Figure 2b). HSPs, aldehyde dehydrogenases and antioxidants were impaired. GOX was the only exception and was significantly up-regulated in EXP, STAT and DECL ( $\mathrm{p}<0.05$ for EXP and $\mathrm{p}<0.001$ for STAT and DECL). The increase was a time-dependent with maximum upregulation of more than 4-fold in DECL (Figure 2b).

\section{$\mathrm{CO}_{2}$-enrichment and combinations}

$\mathrm{CO}_{2}$-bubbling for only four hours, did not induce different expression level changes in the genes of interest 


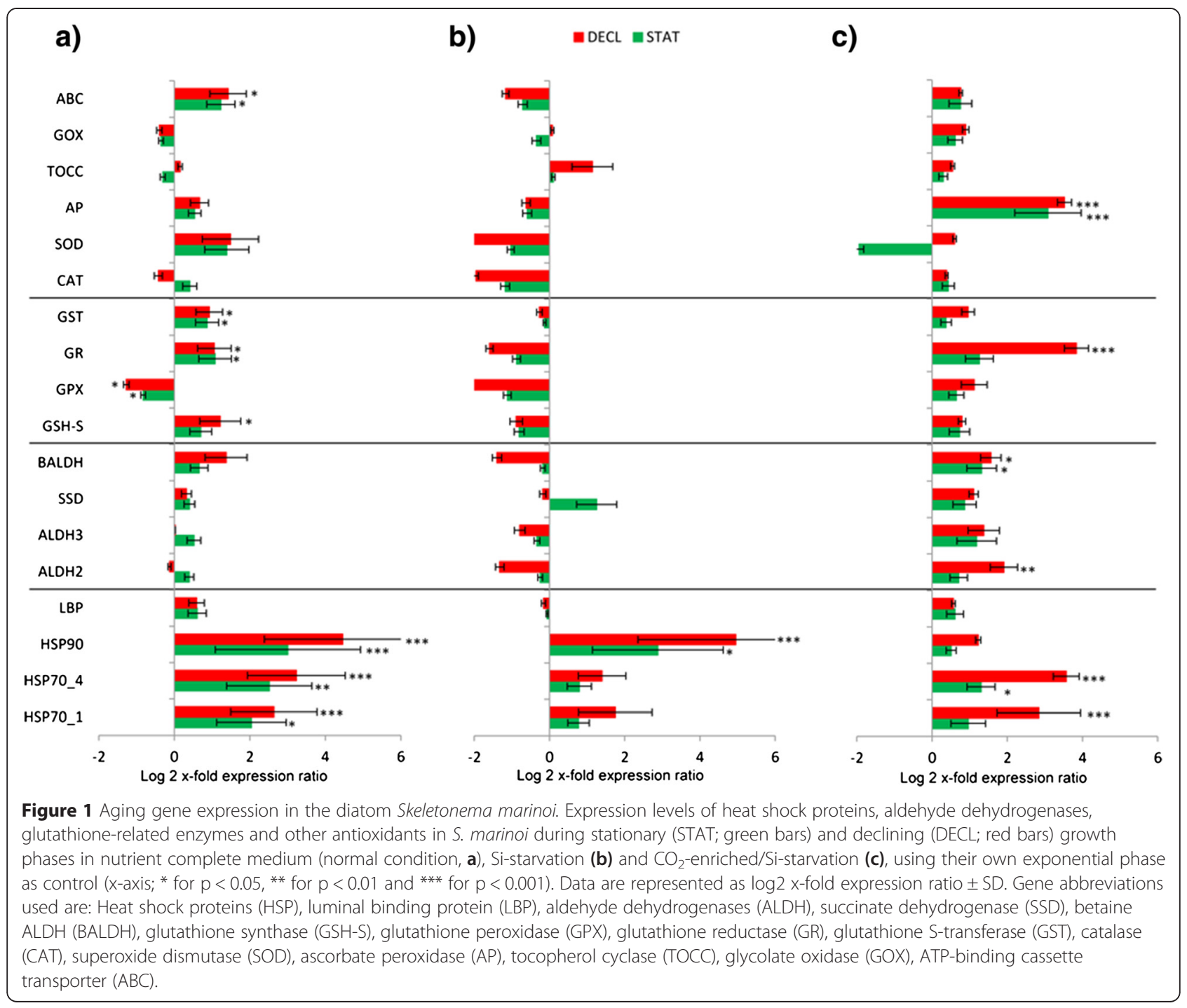

(Figure 3a), but algae grown in $\mathrm{CO}_{2}$-Si condition for four hours showed increased levels of HSP70_4, HSP90, BALDH, GOX and ABC ( $p<0.05$ for GOX and $\mathrm{p}<0.001$ for the others) and a decrease in ALDH2, CAT, SOD and AP ( $<<0.001$ for SOD and $\mathrm{p}<0.05$ for the others) (Figure 3b). Finally, using $\mathrm{CO}_{2}$-enriched medium for the entire growth curve (Figure 4a) there was the down-regulation of almost all the genes, with the lowest reduction in ALDH3 (10-x fold). HSP70_1 and HSP70_4 were down-regulated in DECL ( $\mathrm{p}<0.001)$, ALDH2 in EXP and STAT ( $p<0.01$ and 0.001, repectively), ALDH3 and SSD in EXP, STAT and DECL $(\mathrm{p}<0.001$ for all $)$ and BALDH only in DECL $(\mathrm{P}<0.05)$. For the glutathionerelated genes and others, GSH-S, GST, CAT, SOD and $\mathrm{ABC}$ decreased in STAT ( $\mathrm{p}<0.01$ for GSH-S and ABC, $\mathrm{p}<0.001$ for the others). GSH-S, GR, CAT, SOD, AP and ABC decreased in STAT ( $p<0.001$ for GST, SOD and AP, $p<0.01$ for the others), whereas GSH-S, GST, CAT,
SOD, TOCC and ABC decreased in DECL $(\mathrm{p}<0.001$ for all). Only AP and GPX showed increased expression levels $(\mathrm{p}<0.05$ for both). When this experimental condition was combined with Si-starvation (Figure $4 \mathrm{~b}$ ) only down-regulation patterns were observed, with the lowest reduction of more than 13-fold (ALDH3; Figure 4b). In EXP, HSP70_1, ALDH2, ALDH3, SSD, GR, GST, SOD and AP were reduced $(\mathrm{p}<0.001$ for ALDH3, SSD, SOD and AP, $p<0.05$ for the others), in STAT, HSP70_1, HSP70_4, ALDH2, ALDH3, SSD, GR, GST and SOD ( $p<0.05$ for HSP70_4, ALDH2, GR and GST, $\mathrm{p}<0.01$ for HSP70_1 and $\mathrm{p}<0.001$ for the others) were reduced while in DECL, HSP70_1, ALDH3, SSD, GSH-S, GST, SOD and TOCC $(\mathrm{p}<0.5$ for HSP70_1, GSH-S, GST, $\mathrm{p}<0.001$ for the others) were reduced. For some genes, changes were not significant (see asterisks in Figures). All the results are summarized in Figure 5. 


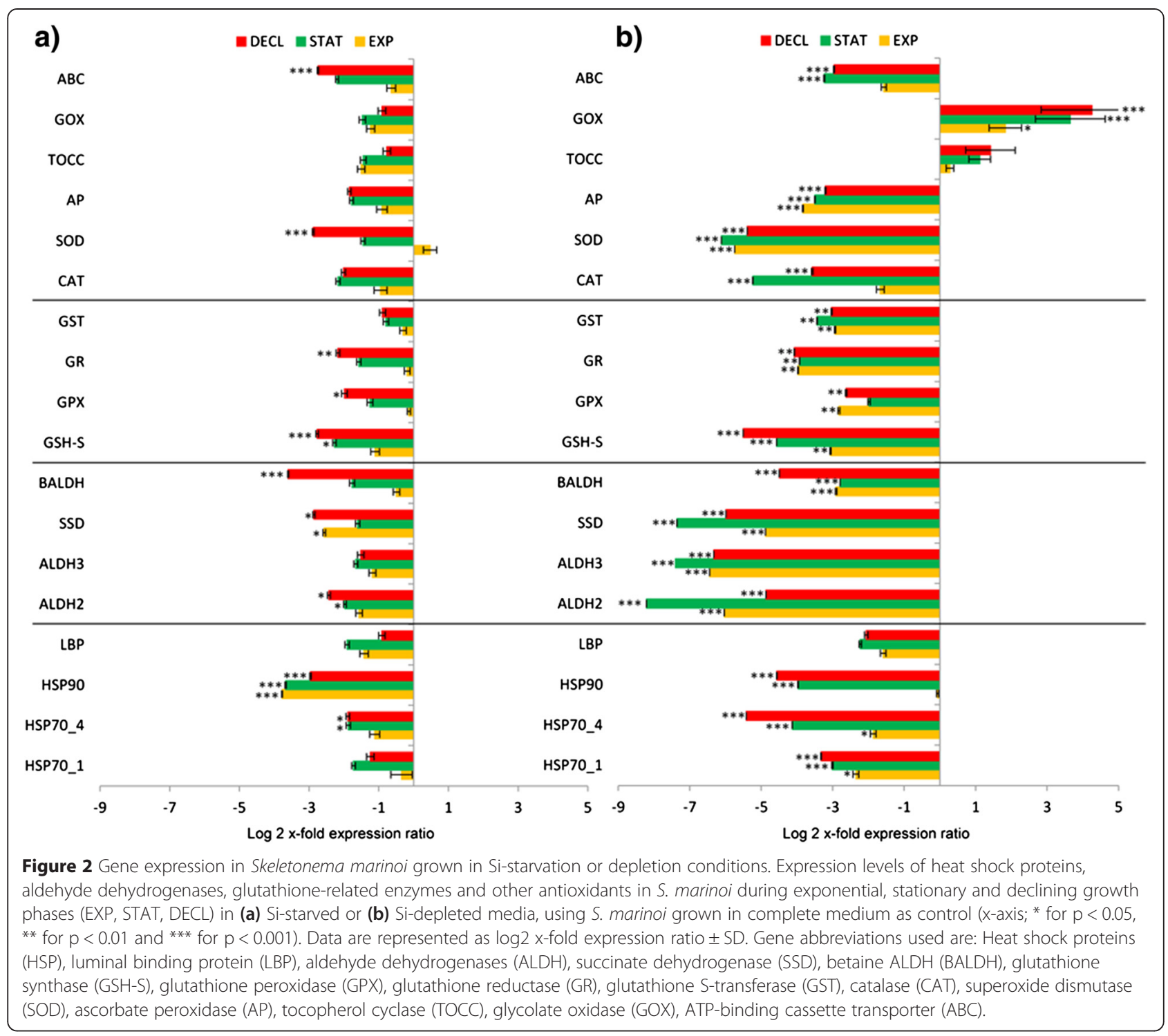

\section{Discussion}

Stress is associated with the generation of reactive oxygen species (ROS). In low quantities, ROS are rapidly converted to less reactive forms, but when present in abnormally high quantities, they can be very damaging to DNA, RNA and proteins. Several studies have reported an increase in the activity of antioxidant ROS-scavenging enzymes also with aging [24], but this has not yet been shown in marine diatoms. Our results indicate that some of the antioxidants (especially glutathione-related enzymes) were up-regulated during aging (in both STAT and $\mathrm{DECL}$ ) in $\mathrm{S}$. marinoi in normal (Figure 1a) and $\mathrm{CO}_{2}-\mathrm{Si}$ conditions (Figure 1c). In addition, our results show that HSP expression levels increase with aging in all conditions tested. An increase in HSPs with aging was first observed in Drosophila melanogaster [25] due to an increase in misfolded proteins and the expression of chaperonines (e.g.
HSPs) for protein re-folding. HSP expression levels increased in both STAT and DECL phases of $S$. marinoi growth (compared to their respective EXP phases, represented in Figure 1 by $x$-axis) in normal (Figure 1a), Si-starvation (Figure $1 \mathrm{~b}$ ), $\mathrm{CO}_{2}$-Si (Figure 1c) and $\mathrm{CO}_{2}$ enrichment (see Additional file 2) conditions. The increase was time-dependent, with the highest up-regulation in the declining phase (Figure 1, in red). On the contrary, aging did not induce changes in expression levels in the other gene categories studied, e.g. ALDHs and other antioxidants. These results suggest the potential use of HSPs and some antioxidants (especially the glutathione-related enzyme GR) as indicators of aging in marine diatoms.

Stress caused by silicic acid and iron starvation induced early aging in the diatom Thalassiosira pseudonana [26]. Here we show that nutrient starvation/depletion (silicic acid) and $\mathrm{CO}_{2}$-enrichment induced early aging in $S$. 


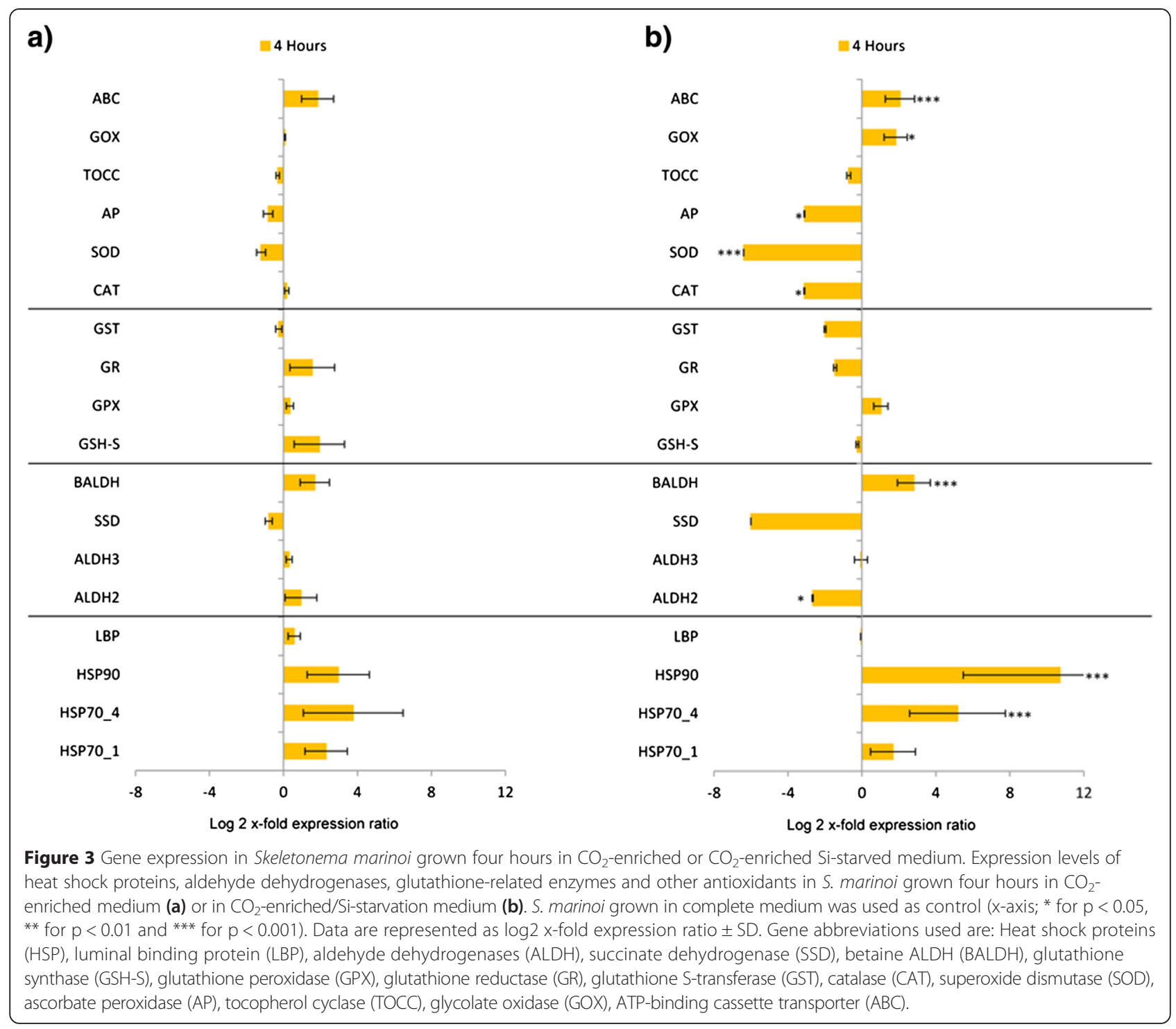

marinoi, as shown by net growth rates. These data suggest that the strongest stressful condition for S. marinoi survival in the present study was the absence of silicates.

We then analysed gene expression levels under two nutrient conditions: reduction of silicic acid in the culturing medium (from $107 \mu \mathrm{M}$ of the control to $36 \mu \mathrm{M}$ ) and complete Si-removal (Figure 2a and b, respectively). Nutrient depletion/reduction did not induce activation of HSPs and the majority of tested genes. In both experiments, expression levels of HSPs, ALDHs, GSH-S, GR, GPX and GST were significantly reduced without silicic acid or in Si-starvation conditions compared to controls (Figure 2a and b). Interestingly, a decrease in expression levels was time-dependent in Si-starvation conditions only for GSH-S, GR, GPX and GST, with highest expression in the exponential phase (EXP) and lowest in the declining phase (DECL) (Figure 2a). Gene down-regulation in cells grown without silicic acid was even more pronounced. In order to understand if the observed downregulation is Si-limitation specific or is common for other nutrient limitation conditions, we also cultivated $S$. marinoi in phosphate-starvation (P-starvation). Results showed that also in this case there was a significant down-regulation of the genes of interest, except for the up-regulation of GOX, of the antioxidant GPX and the chaperonine HSP90 (see Additional file 3). Overall, this reduction in gene expression in response to nutrient starvation may indicate a cell strategy to avoid unnecessary over-investment in the respective proteins, similar to the depression in protein synthesis that occurs in other organisms during environmental stress, considered a substantial bioenergetic saving process [27].

$\mathrm{CO}_{2}$-enrichment is reported to induce contrasting results in phytoplankton, with more or less tolerant species, such as Cyanidium caldarium and Tetraselmis sp, 


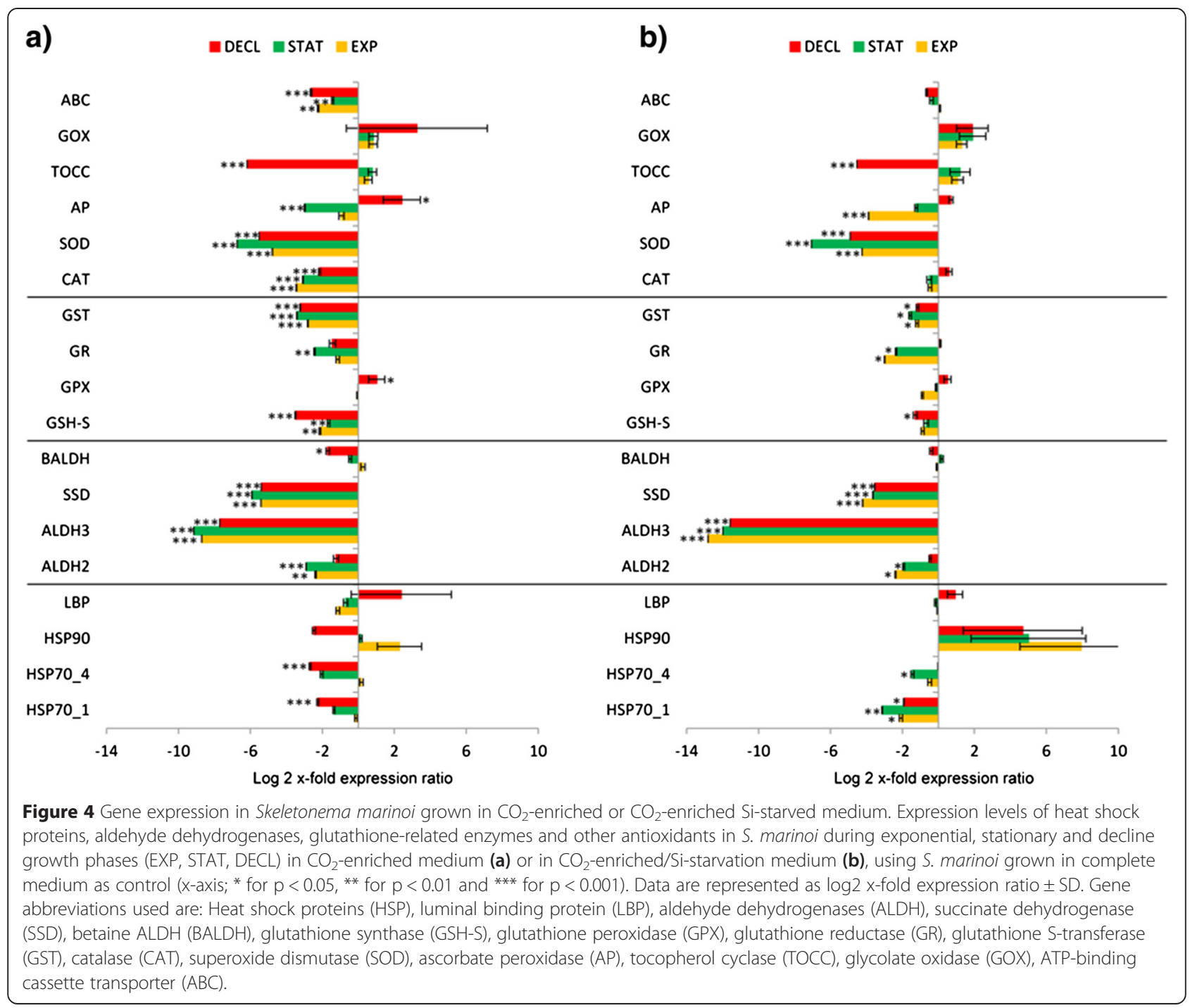

respectively [28]. Engel et al. [29] carried out a mesocosm experiment to document the effect of $\mathrm{CO}_{2}$ concentration on a bloom of the haptophyte algae Emiliania huxleyi, which supported earlier findings of reduced calcification at higher $\mathrm{CO}_{2}$ concentrations. Hutchins et al. [30] studied dinitrogen $\left(\mathrm{N}_{2}\right)$ and $\mathrm{CO}_{2}$ fixation rates under future $\mathrm{CO}_{2}$ scenarios in the marine cyanobacteria Trichodesmium, which contributes a large fraction of the new nitrogen entering the oligotrophic oceans. They suggested that predicted elevated $\mathrm{CO}_{2}$ levels in the future could alter current marine $\mathrm{N}$ and $\mathrm{C}$ cycles. Here, we tested the effect of $\mathrm{CO}_{2}$-enrichment, alone or in combination with Si-starvation, after four hours and after prolonged exposure (7 days). After 4 hours of $\mathrm{CO}_{2}$ enrichment, various genes were up-regulated (e.g. HSPs, ALDHs and some antioxidants; Figure 3a), but after prolonged exposure (Figure 4a) these levels were significantly reduced, suggesting that the activation of these genes may be only a short-term stress signal. Copper stress induced a similar response in the diatom Thalassiosira pseudonana [31]. This diatom exhibited a rapid induction of certain $\mathrm{Cu}$-related genes to elevated concentrations of copper (after $1 \mathrm{~h}$-exposure), but this response was attenuated over $24 \mathrm{~h}$ of continuous exposure. The down-regulation observed in $\mathrm{CO}_{2}$-enrichment experiments (Figures $3 \mathrm{~b}, 4 \mathrm{a}$ and 4b) may be an energetic cost-saving strategy used by organisms to allow restoration of homeostasis and survival [27].

In contrast to most of the stress-related genes studied here, glycolate oxidase (GOX) was up-regulated in $\mathrm{Si}$ depletion, after prolonged $\mathrm{CO}_{2}$-bubbling, $\mathrm{CO}_{2}$-Si, and P-starvation (Figures 2b, 4a, 4b). Glycolate oxidizing enzyme is known to play a key role in photorespiratory carbon metabolism responsible for reducing carbon loss and oxidative damage [32]. However, photorespiration also plays other roles in higher plants e.g. amino acid metabolism, nitrate reduction, stress resistance, and signal transduction [32,33]. Our results suggest a specific protective antioxidant activity for GOX that does not 


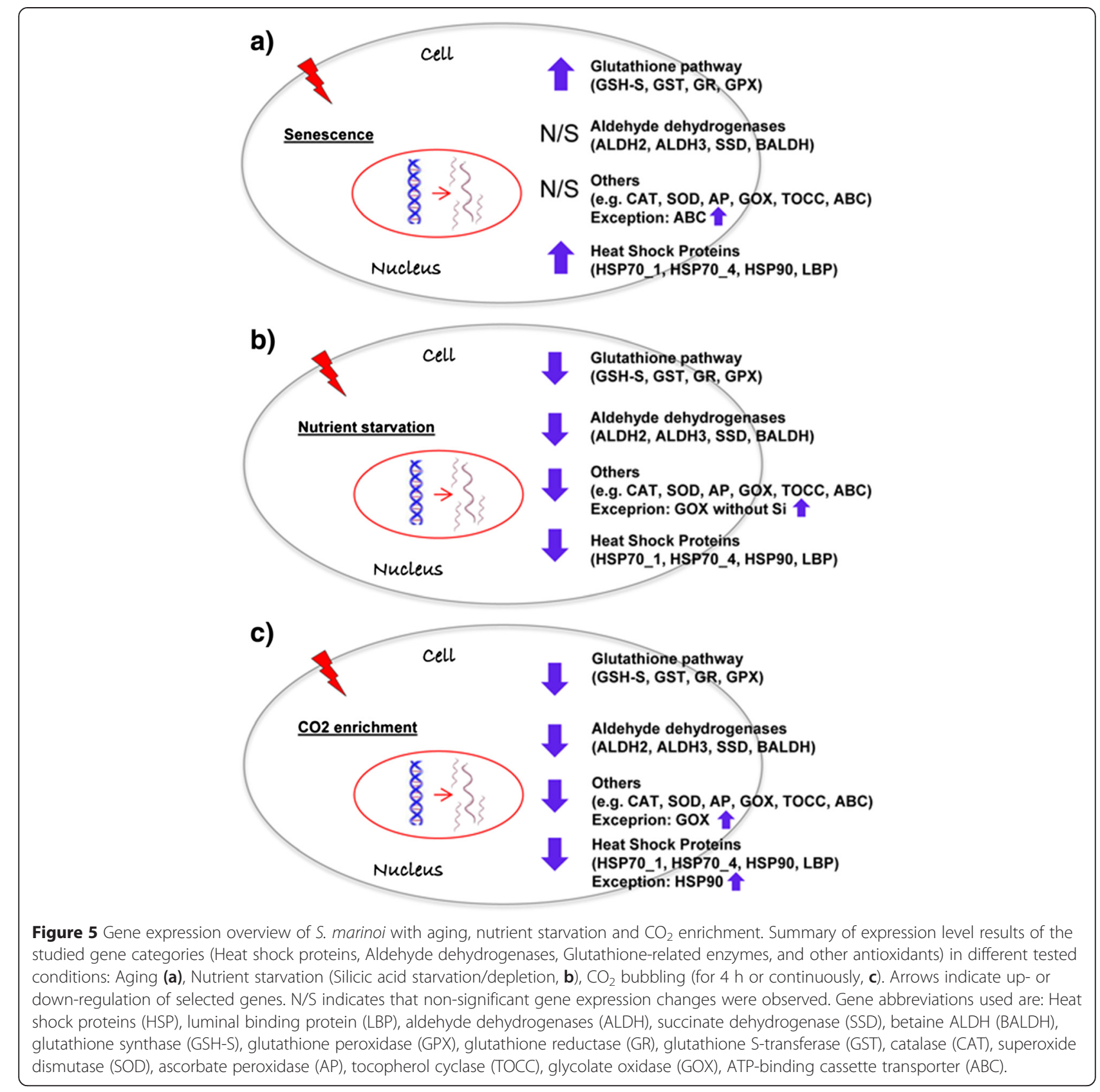

always imply a change in $\mathrm{C}$ metabolism, as also found in the higher plants Arabidopsis thaliana and Oryza sativa [32,33].

\section{Conclusions}

Our results provide first insights on early warning signals for environmental stressful conditions, such as those predicted under a Global Climate Change scenario, in the ubiquitous diatom Skeletonema marinoi (as summarized in Figure 5). Nutrient starvation/depletion, $\mathrm{CO}_{2}$-enrichment and the combined effect of stressors, impact the growth rate of this species, inducing early aging.
HSPs behave as signals of senescence/aging (Figure 5a) and short-term exposure to stress (i.e. HSP90; Figure 5c) whereas the antioxidant GOX as a signal of strong nutrient depletion (silicic acid) and/or exposure to high $\mathrm{CO}_{2}$ concentration with or without Si-starvation (Figure 5b,c).

\section{Methods}

\section{Cell culturing and harvesting}

Skeletonema marinoi (CCMP2501) was grown in Guillard's f/2 medium [34] in two-liter polycarbonate bottles (each experiment was performed in triplicate) 
constantly bubbled with air filtered through $0.2 \mu \mathrm{m}$ membrane filters. For the $\mathrm{Si}$ - and P-starvation experiments medium was prepared with low concentration of silicic acid $\left(36 \mu \mathrm{M} \mathrm{Si}(\mathrm{OH})_{4}\right)$ and with low concentration of phosphate $\left(0.5 \mu \mathrm{MPO}_{4}^{2-}\right)$, respectively. $\mathrm{CO}_{2}$-enrichment (alone or in combination with $\mathrm{Si}$-starvation, referred to as $\mathrm{CO}_{2}-\mathrm{Si}$ ) was obtained through continuous $\mathrm{CO}_{2}$-bubbling for few hours $(4 \mathrm{~h})$ or during the entire growth curve (until day 7), using the $\mathrm{CO}_{2}$ dispenser RuWal (RuWal aquatech). The experimental $\mathrm{pH}$ value was 6.5 (control $\mathrm{pH}$ was about 8 ). Cultures were kept in a climate chamber at $19^{\circ} \mathrm{C}$ on a $12: 12 \mathrm{~h}$ light:dark cycle at $100 \mu \mathrm{mol}$ photons $\mathrm{m}^{-2} \mathrm{~s}^{-1}$. Initial cell concentrations were about 5000 cells $/ \mathrm{mL}$ for each experiment and culture growth rate was monitored, using the equation for net growth estimates [35]. A $50 \mathrm{~mL}$ culture aliquot was sampled each day (from day 3 to day 7 after inoculation, at the same time of the day to avoid possible interference by intrinsic circadian rhythms), and centrifuged for 30 minutes at $4^{\circ} \mathrm{C}$ at $3900 \mathrm{~g}$ (Eppendorf, 5810R). The pellet was re-suspended in $500-800 \mu \mathrm{L}$ of TRIZOLC (Invitrogen, Carlsbad, CA), incubated for 2-3 minutes at $60^{\circ} \mathrm{C}$ until completely dissolved and kept at $-80^{\circ} \mathrm{C}$ until RNA extraction.

\section{RNA extraction and CDNA synthesis}

For RNA extraction, cells were lysed using half a spatula of glass beads (about $200 \mathrm{mg}$; Sigma-Aldrich, Milan, Italy) for each $2 \mathrm{~mL}$ tube, incubating and mixing tubes for $10 \mathrm{~min}$ at $60^{\circ} \mathrm{C}$ and maximum speed in the Thermo Shaker BS100 (Biosan). RNA was then extracted using TRIZOL@ manufacturer's protocol. RNA quantity and purity were assessed by Nano-Drop (ND-1000 UV-Vis spectrophotometer; NanoDrop Technologies) monitoring the absorbance at $260 \mathrm{~nm}$ and the $260 / 280 \mathrm{~nm}$ and 260/230 nm ratios (Both ratios were about 2.0). RNA quality was evaluated by gel electrophoresis that showed intact RNA, with sharp ribosomal bands. $500 \mathrm{ng}$ of each RNA were retrotranscribed into complementary DNA (cDNA) with the iScriptTM cDNA Synthesis Kit (BIORAD, Hercules, CA) following the manufacturer's instructions.

\section{Oligo design}

Primers for genes of interest (GOI) were designed using the software Primer3 v. 0.4.0 (http://frodo.wi.mit.edu/ primer3/) considering sequences from the transcriptome of the diatom Skeletonema marinoi deposited in the public database CAMERA (http://camera.crbs.ucsd.edu/ mmetsp/list.php) and in iMicrobe, interactive query tool for microbial data (http://data.imicrobe.us/sample/view/ 1867). See Additional file 1 for selected GOI, their functions, primers' sequences, efficiencies and correlation factor. Primers were optimized in a GeneAmp PCR System 9700 (Perkin Elmer). For a detailed description see [11].

\section{Reverse transcription-quantitative polymerase chain reaction ( $R T-q P C R)$}

In order to normalize expression levels of specific GOI, a panel of putative reference genes (RGs), was first screened in the experimental conditions: entire growth curve in normal condition (data not shown), total Siexperiment (both growth without silicic acid and silica starvation), total $\mathrm{CO}_{2}$ experiment (growth in $\mathrm{CO}_{2}$-enriched water for a few hours or along the entire growth curve), $\mathrm{CO}_{2}$-Si and P-starvation. Three different algorithms were utilized to identify the best RGs in our experimental design: BestKeeper [36], geNorm [37] and NormFinder [38]. See Additional file 4 for specific RGs for each experiment.

Serial dilutions of cDNA were used to determine GOI primer reaction efficiency (E) and correlation factor $\left(R^{2}\right)$ (see Additional file 1). Standard curves were generated with five dilution points by using the cycle threshold (Ct) value versus the logarithm of each dilution factor and using the equation $\mathrm{E}=10^{-1 / \text { slope }}$. RT-qPCR was performed in MicroAmp Optical 384-Well reaction plate (Applied Biosystem, Foster City, CA) with optical adhesive covers (Applied Biosystem) in a Viia7 real-time PCR system (Applied Biosystem) and using the fluorescent dye Fast Start SYBR Green Master Mix (Roche, Indianapolis, IN). The PCR volume for each sample was $10 \mu \mathrm{l}$, with $5 \mu \mathrm{l}$ of Fast Start SYBR Green Master Mix, $1 \mu$ l of cDNA template (1:50 template dilution) and $0.7 \mathrm{pmol} / \mathrm{mL}$ for each oligo. The RT-qPCR thermal profile was obtained using the following procedure: $95^{\circ} \mathrm{C}$ for $20 \mathrm{~s}, 40$ times $95^{\circ} \mathrm{C}$ for $1 \mathrm{~s}$, and $60^{\circ} \mathrm{C}$ for $20 \mathrm{~s}$. The program was set to reveal the melting curve of each amplicon from 60 to $95^{\circ} \mathrm{C}$, and read every $0.5^{\circ} \mathrm{C}$. Only a single peak was identified in the melting-curve analyses of all genes, confirming a gene-specific amplification and the absence of primer-dimers. All RT-qPCR reactions were carried out in triplicate to capture intra-assay variability and included three no-template negative controls (NTC) for each primer pair. To study expression levels for each GOI relative to the most stable RGs, we used the REST tool (Relative Expression Software Tool) [39]. Control conditions changed depending on the specific experiment (See Figure legends for each specific case). Statistical analysis was performed using the Pair Wise Fixed Reallocation Randomisation test by REST [39] and GraphPad Prim statistic software, V4.00 (GraphPad Software).

\section{Availability of supporting data}

Sequences of the transcriptome of the diatom Skeletonema marinoi are deposited in the public database 
CAMERA (http://camera.crbs.ucsd.edu/mmetsp/list.php) and in iMicrobe, interactive query tool for microbial data (http://data.imicrobe.us/sample/view/1867).

\section{Additional files}

\begin{abstract}
Additional file 1: Lists selected genes of interest, their abbreviations and functions, sequences of forward and reverse primers, efficiencies (E) and correlation factor (R). Gene abbreviations used are: Heat shock proteins (HSP), luminal binding protein (LBP), aldehyde dehydrogenases (ALDH), succinate dehydrogenase (SSD), betaine ALDH (BALDH), glutathione synthase (GSH-S), glutathione peroxidase (GPX), glutathione reductase (GR), glutathione S-transferase (GST), catalase (CAT), superoxide dismutase (SOD), ascorbate peroxidase (AP), tocopherol cyclase (TOCC), glycolate oxidase (GOX), ATP-binding cassette transporter (ABC).
\end{abstract}

Additional file 2: Aging gene expression in the diatom Skeletonema marinoi in the $\mathrm{CO}_{2}$-enriched condition. Expression levels of heat shock proteins, aldehyde dehydrogenases, glutathione-related enzymes and other antioxidants in S. marinoi during stationary (STAT; green bars) and declining (DECL; red bars) growth phases in the $\mathrm{CO}_{2}$-enriched condition, using the exponential phase as control ( $x$-axis; ${ }^{*}$ for $p<0.05,{ }^{* *}$ for $p<$ 0.01 and $* * *$ for $p<0.001)$. Data are represented as $\log 2 x$-fold expression ratio \pm SD. Gene abbreviations used are: Heat shock proteins (HSP), luminal binding protein (LBP), aldehyde dehydrogenases $(A L D H)$, succinate dehydrogenase (SSD), betaine ALDH (BALDH), glutathione synthase $(G S H-S)$, glutathione peroxidase (GPX), glutathione reductase (GR), glutathione S-transferase (GST), catalase (CAT), superoxide dismutase (SOD), ascorbate peroxidase (AP), tocopherol cyclase (TOCC), glycolate oxidase (GOX), ATP-binding cassette transporter (ABC).

Additional file 3: Gene expression in Skeletonema marinoi grown in P-starved medium. Expression levels of heat shock proteins, aldehyde dehydrogenases, glutathione-related enzymes and other antioxidants in S. marinoi during exponential, stationary and declining growth phases (EXP, STAT, DECL) in P-starved medium, using $S$. marinoi grown in complete medium as control ( $x$-axis; ${ }^{*}$ for $p<0.05$, ${ }^{* *}$ for $p<0.01$ and ${ }^{* * *}$ for $p<0.001$ ). Data are represented as log $2 x$-fold expression ratio \pm SD. Gene abbreviations used are: Heat shock proteins (HSP), luminal binding protein (LBP), aldehyde dehydrogenases (ALDH), succinate dehydrogenase (SSD), betaine ALDH (BALDH), glutathione synthase (GSH-S), glutathione peroxidase (GPX), glutathione reductase (GR), glutathione S-transferase (GST), catalase (CAT), superoxide dismutase (SOD), ascorbate peroxidase (AP), tocopherol cyclase (TOCC), glycolate oxidase (GOX), ATP-binding cassette transporter (ABC)

\section{Additional file 4: Best reference genes in the experimental} conditions analyzed. Best reference genes as given by BestKeeper, NormFinder and Genorm analyses, for each of the experimental conditions studied: Silicic acid-starvation/depletion experiments, $\mathrm{CO}_{2}$ experiments ( $\mathrm{CO}_{2}$ for four hours or for the entire growth curve), Si-starvation combined with $\mathrm{CO}_{2}$-enrichment and phosphate-starvation.

\section{Abbreviations}

(ALDH): Aldehyde dehydrogenases; (AP): Ascorbate peroxidase; (ABC): ATP-binding cassette transporter; (BALDH): Betaine ALDH; $\left(\mathrm{CO}_{2}\right)$ : Carbon Dioxide; (CAT): Catalase; $\left(\mathrm{CO}_{2}\right.$-Si): $\mathrm{CO}_{2}$-enrichment in combination with Si-starvation condition; (CDNA): Complementary DNA; (Ct): Cycle threshold; (DECL): Decline; $\left(\mathrm{N}_{2}\right)$ : Dinitrogen; (EXP): Exponential phase; (GOl): Genes of interest; (GPX): Glutathione peroxidase; (GR): Glutathione reductase; (GST): Glutathione S-transferase; (GSH-S): Glutathione synthase; (GOX): Glycolate oxidase; (HSP): Heat shock proteins; (LBP): Luminal binding protein; (NTC): No-template negative controls; (P-starvation): Phosphate starvation; (ROS): Reactive oxygen species; (RGs): Reference genes; PCR (RT-gPCR): Reverse Transcription-quantitative; (Si-starvation): Silicic acid starvation; (STAT): Stationary; (SSD): Succinate dehydrogenase; (SOD): Superoxide dismutase; (TOCC): Tocopherol cyclase.

\section{Competing interests}

The authors declare that they have no competing interests.

\section{Authors' contributions}

$\mathrm{CL}$ conceived and designed the experiments, performed the experiments, analysed the data and co-wrote the paper. 10 designed and performed the experiments, analysed the data and co-wrote the paper. GP performed the experiments and co-wrote the paper. GR conceived and designed the experiments and co-wrote the paper. Al conceived and designed the experiments and co-wrote the paper. All authors read and approved the final manuscript.

\section{Acknowledgments}

The authors thank the staff of the Molecular Biology Service of the Stazione Zoologica Anton Dohrn for their technical support. We would like to thank Maria Cristina Gambi and Maurizio Ribera d'Alcalà for fruitful discussion and Daniele De Luca for technical assistance. Ida Orefice has been supported by a Stazione Zoologica Anton Dohrn PhD fellowship. This research was funded in part by the Gordon and Betty Moore Foundation through Grant \#2637 to the National Center for Genome Resources.

Received: 3 February 2015 Accepted: 24 April 2015

Published online: 28 May 2015

\section{References}

1. Verity PG, Smetacek V. Organism life cycles, predation, and structure of pelagic ecosystems. Mar Ecol Prog Ser. 1996;130:277-93.

2. Falkowski P. The role of phytoplankton photosynthesis in global biogeochemical cycles. Photosynth Res. 1994;39(3):235-58.

3. Nelson DM, Tréguer P, Brzezinski MA, Leynaert A, Quéguiner B. Production and dissolution of biogenic silica in the ocean: revised global estimates, comparison with regional data and relationship to biogenic sedimentation. Global Biogeochem Cy. 1995;9(3):359-72.

4. Lommer M, Specht M, Roy AS, Kraemer L, Andreson R, Gutowska M, et al. Genome and low-iron response of an oceanic diatom adapted to chronic iron limitation. Genome Biol. 2012;13:R66.

5. Sun J, Hutchins DA, Feng Y, Seubert EL, Caron DA, Fu FX. Effects of changing $\mathrm{pCO}_{2}$ and phosphate availability on domoic acid production and physiology of the marine harmful bloom diatom Pseudo-nitzschia multiseries. Limnol Oceanogr. 2011;56(3):829-40.

6. Miralto A, Barone G, Romano G, Poulet SA, lanora A, Russo GL, et al. The insidious effect of diatoms on copepod reproduction. Nature. 1999;402(6758):173-6.

7. Ianora A, Miralto A, Poulet SA, Carotenuto Y, Buttino I, et al. Aldehyde suppression of copepod recruitment in blooms of a ubiquitous planktonic diatom. Nature. 2004;429(6990):403-7.

8. Godhe A, Harnstrom K. Linking the planktonic and benthic habitat:genetic structure of the marine diatom Skeletonema marinoi. Mol Ecol. 2010;19:4478-90

9. Fontana A, D'lppolito G, Cutignano A, Miralto A, lanora A, Romano G, et al. Chemistry of oxylipin pathways in marine diatoms. Pure Appl Chem. 2007;79(4):481-90.

10. Ribalet F, Wichard T, Pohnert G, lanora A, Miralto A, Casotti R. Age and nutrient limitation enhance polyunsaturated aldehyde production in marine diatoms. Phytochemistry. 2007;68:2059-67.

11. Lauritano C, Borra M, Carotenuto Y, Biffali E, Miralto A, Procaccini G, et al. First molecular evidence of diatom effects in the copepod Calanus helgolandicus. J Exp Mar Biol Ecol. 2011;404:79-86.

12. Lauritano C, Borra M, Carotenuto Y, Biffali E, Miralto A, Procaccini G, et al. Molecolar evidence of the toxic effects of diatom diets on gene expression patterns in copepods. PLoS One. 2011;6, e26850.

13. Ribera d'Alcalà M, Civitarese G, Conversano F, Lavezza R. Nutrient ratios and fluxes hint at overlooked processes in the Mediterranean Sea. J Geophys Res. 2003;108(C9):8106.

14. Gao K, Campbell DA. Photophysiological responses of marine diatoms to elevated $\mathrm{CO}_{2}$ and decreased pH: a review. Funct Plant Biol. 2014;41:449-59.

15. Otzen D. The role of proteins in biosilicification. Scientifica. 2012;2012:867562.

16. Sapriel G, Quinet M, Heijde M, Jourdren L, Tanty V, Luo G, et al. Genome-wide transcriptome analyses of silicon metabolism in Phaeodactylum tricornutum reveal the multilevel regulation of silicic acid transporters. PLoS One. 2009; 4(10), e7458

17. Boyce DG, Lewis MR, Worm B. Global phytoplankton decline over the past century. Nature. 2010;466:591-6. 
18. Mutshinda CM, Troccoli-Ghinaglia L, Finkel ZV. Environmental control of the dominant phytoplankton in the Cariaco basin: a hierarchical Bayesian approach. Mar Biol Res. 2013;9:247-61.

19. Bard SM. Multixenobiotic resistance as a cellular defense mechanism in aquatic organisms. Aquat Toxicol. 2000;48:357-89.

20. Mittler R. Oxidative stress, antioxidants and stress tolerance. TRENDS in Plant Sci. 2002;7(9):405-10.

21. Marchitti SA, Brocker C, Stagos D, Vasiliou V. Non-P450 aldehyde oxidizing enzymes: the aldehyde dehydrogenase superfamily. Drug Metab Toxicol. 2008;4:697-720.

22. Rojas CM, Senthil-Kumar M, Wang K, Ryu CM, Kaundal A, Mysore KS. Glycolate Oxidase Modulates Reactive Oxygen Species-Mediated Signal Transduction during Nonhost Resistance in Nicotiana benthamiana and Arabidopsis. Plant Cell. 2012;24:336-52

23. Sorensen JG, Kristensen TN, Loeschcke V. The evolutionary and ecological role of heat shock proteins. Ecol Lett. 2003;6:1025e1037.

24. Judge $\mathrm{S}$, Jang YM, Smith A, Hagen T, Leeuwenburgh C. Age-associated increases in oxidative stress and antioxidant enzyme activities in cardiac interfibrillar mitochondria: implications for the mitochondrial theory of aging. FASEB J. 2005;19(3):419-21.

25. Wheeler JC, Bieschke ET, Tower J. Muscle-specific expression of Drosophila hsp70 in response to aging and oxidative stress. Proc Natl Acad Sci. 1995;92:10408-12.

26. Mock T, Samanta MP, Iverson V, Berthiaume C, Robison M, Holtermann K, et al. Whole-genome expression profiling of the marine diatom Thalassiosira pseudonana identifies genes involved in silicon bioprocesses. Proc Natl Acad Sci U S A. 2008;105(5):1579-84.

27. Hand SC, Hardewig I. Downregulation of cellular metabolism during environmental stress: mechanisms and implications. Annu Rev Physio. 1996;58:539-63.

28. Salih FM. Microalgae Tolerance to High Concentrations of Carbon Dioxide: A Review. J Envir Protect Sci. 2011;2:648-54.

29. Engel A, Zondervan I, Aerts K, Beaufort L, Benthien A, Chou L, et al. Testing the direct effect of $\mathrm{CO}_{2}$ concentration on a bloom of the coccolithophorid Emiliania huxleyi in mesocosm experiments. Limnol Oceanogr. 2005:50(2):493-507

30. Hutchins DA, Fu FX, Zhang Y, Warner ME, Feng Y, Portune $K$, et al. CO control of Trichodesmium $\mathrm{N}_{2}$ fixation, photosynthesis, growth rates, and elemental ratios: Implications for past, present, and future ocean biogeochemistry. Limnol Oceanogr. 2007;52(4):1293-304.

31. Davis AK, Hildebrand M, Palenik B. Gene Expression Induced by Copper Stress in the Diatom Thalassiosira pseudonana. Eukaryot Cell. 2006;5(7):1157-68.

32. Chern M, Bai W, Chen X, Canlas PE, Ronald PC. Reduced expression of glycolate oxidase leads to enhanced disease resistance in rice. Peer J. 2013;1, e28.

33. Moreno Jl, Martin R, Castresana C. Arabidopsis SHMT1, a serine hydroxymethyltransferase that functions in the photorespiratory pathway influences resistance to biotic and abiotic stress. Plant J. 2005:41(3):451-63.

34. Guillard RRL. Culture of phytoplankton for feeding marine invertebrates. In: Smith WL, Chanley MH, editors. Culture of Marine Invertebrate Animals. New York, USA.: Plenum Press; 1975. p. 26-60.

35. Escalera L, Reguera B, Moita T, Pazos Y, Cerejo M, Cabanas JM, et al. Bloom dynamics of Dinophysis acuta in an upwelling system: In situ growth versus transport. Harmful Algae. 2010;9:312-22.

36. Pfaffl MW, Tichopad A, Prgomet C, Neuvians TP. Determination of stable housekeeping genes, differentially regulated target genes and sample integrity: BestKeeper - Excel-based tool using pair-wise correlations. Biotechnol Lett. 2004;26(6):509-15.

37. Vandesompele J, De Preter K, Pattyn F, Poppe B, Van Roy N, De Paepe A, et al. Accurate normalization of real-time quantitative RT-PCR data by geometric averaging of multiple internal control genes. Genome Biol. 2002;3:7.

38. Andersen $\mathrm{CL}$, Jensen $\mathrm{J}$, Orntoft TF. Normalization of real-time quantitative reverse transcription-PCR data: A model-based variance estimation approach to identify genes suited for normalization, applied to bladder and colon cancer data sets. Cancer Res. 2004;64(15):5245-50.

39. Pfaffl MW, Horgan GW, Dempfle L. Relative expression software tool (REST (c)) for group-wise comparison and statistical analysis of relative expression results in real-time PCR. Nucleic Acids Res. 2002:30:9.

\section{Submit your next manuscript to BioMed Central and take full advantage of:}

- Convenient online submission

- Thorough peer review

- No space constraints or color figure charges

- Immediate publication on acceptance

- Inclusion in PubMed, CAS, Scopus and Google Scholar

- Research which is freely available for redistribution 